\title{
A GeOMETRICAL MODEL FOR TIRES UNDER VeRTICAL LOADING
}

\author{
Ronaldo B. Salvagni ${ }^{1}$, Marcelo A. L. Alves ${ }^{1}$, Roberto S. Barbosa ${ }^{1}$ \\ ${ }^{1}$ University of São Paulo - Escola Politecnica, São Paulo, Brasil \\ E-mail: salvagni@usp.br
}

\begin{abstract}
The existing tire models are basically of three kinds: essentially empirical ("magic formulas"), or mixed empirical/analytical, or extremely complex theoretical models almost useless in practical situations. The model here proposed does not require any empirical data, and presents a simple theoretical approach very suitable to use in project and analysis of real suspension systems.

This paper presents a physical and mathematical model for the mechanical behavior of pneumatic car tires, in the particular case of vertical loading. It is a theoretical model, in the sense that it does not require any empirical data. It is based on the perfectly flexible and quasi-inextensible membrane theory, and its formulation does not rely on any tire material property - it is exclusively geometric.

The calculated results from this model are compared with measured data from four quite different types of tires: two used in small passenger cars, one high performance tire used in sport vehicles, and other heavy duty tire used in SUV's. In all cases, the differences between measured and calculated data were lower than $5 \%$ in the normal range of pressure and loading.
\end{abstract}

\section{INTRODUCTION}

Tire is the structural vehicle component that exchange forces and moments with road surface to support and control vehicle attitude. Means to deal with the rolling contact phenomena are relevant tools for vehicle dynamics engineer and the tire designer. It is usual to formulate empirical expression based on experimental data to describe tire behavior. This approach does not have any physical or mechanical fundamental relationship with the tire structure itself. Several models with different approach, purpose, level of complexity and accuracy have been proposed by various authors during last half century, accessing only partial aspects of this complex system. Finite element method (Nakashima, Wong, 1993), multi radial spoke model or brush model (Sharp and El-Nashar, 1986), (Duggof, Fancher, Segel, 1970, Pacejka, 1972), flexible ring model (Miège, 2004), membrane model (Zachow, 1997) shell model (Lecomte, 2010), modal synthesis method (Guan, 1999, Shang 2002), experimental data multiparametric polynomial interpolation (Bakker,(Delft) 1987, Segel et el (UMTRI Michigan) 1977, Pacejka (Delft) 1993) are some examples.

In this text, the mechanical behavior of an pneumatic tire will be represented by a structural model called "membrane", or "thin walled involucres" (Timoshenko (1964), Pissarenko(1985)), which physical and mathematical models will be presented in the next 
item. The interface region between the tire and the road will be focused, with the goal of obtaining a detailed distribution of the forces systems acting in this region. The appropriate integration of these forces systems will give the values of the forces and moments acting at the vehicle suspension system.

This model is essentially different from those presented by several authors (for instance, Böhm (1966), Vil’ke (1998, 2001 and 2004), Pacejka (2006)).

This paper presents an approach to the vertical model only. The vertical deflection of different types of actual tires, calculated using the model here proposed, is compared with measured data.

\section{PHYSICAL MODEL - MEMBRANE}

The physical model adopts the following hypothesis and simplifications:

1 - The tire is represented by three (03) geometrical surfaces, as shown in Figure 2.1, which are defined by:

a) Two equal and symmetrical side walls, seen in Figure 2.2 (internal and external surfaces), constituted by the partial section of a toroidal surface defined by the following dimensions: the external tire radius $(R e)$, its internal radius or the wheel radius $(\mathrm{Ri})$ and the "curvature parameter" or "bulging parameter" $(c o)$ shown at the Figure 2.2, for the tire without loading.

b) The tread, also in Figure 2.2, represented by the orthogonal section of a cylinder, is defined by the "equivalent" external radius of the tire (Reb) and the breadth of the tread (L). Note: Reb may be a little different from $R e$ but, in principle, $R e=R e b$.

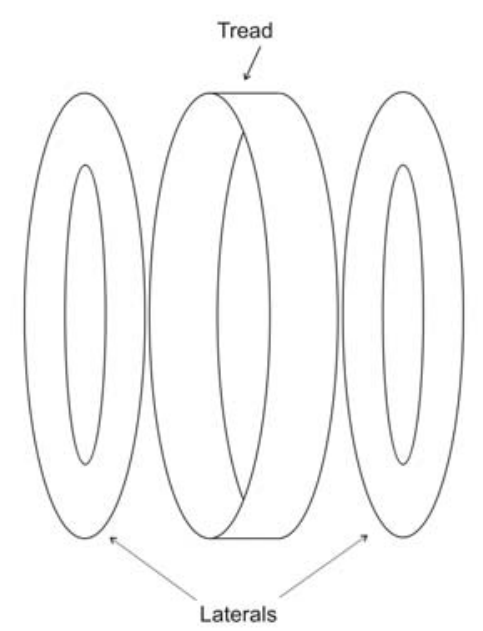

Figure 2.1 - Membrane model 
2 - The side walls are geometrical surfaces (with no thickness) and they behave as ideal membranes, i.e., they are perfectly flexible (there is no bending stiffness) and they are inextensible (there are no deformation along the surface).

3 - The tread is also a geometrical surface (with no thickness) and it also behaviors as ideal membrane. But, for some effects (e.g., the longitudinal slip), this hypothesis may be used just partially.

4 - For the side walls, the membrane stresses intensity (modulus) will remain constant under the several loads, and just their direction will change. The directions changes will occur according the respective changes of the surfaces geometry, under the corresponding loading cases.

5 - The internal volume of the tire is constant and, with constant temperature, the internal gas pressure does not change under loadings.

6 - The contact region between the tire and the ground is a plane quadrilateral.

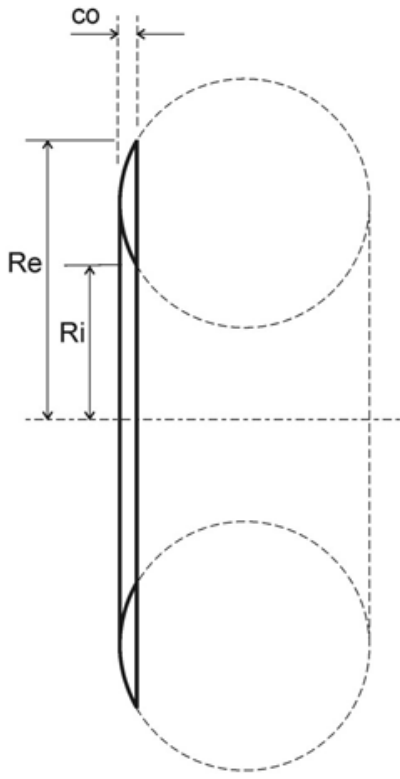

a. One Side wall

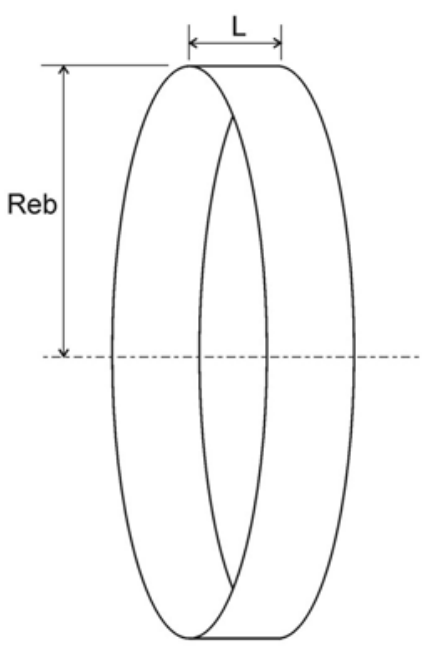

b. Tread

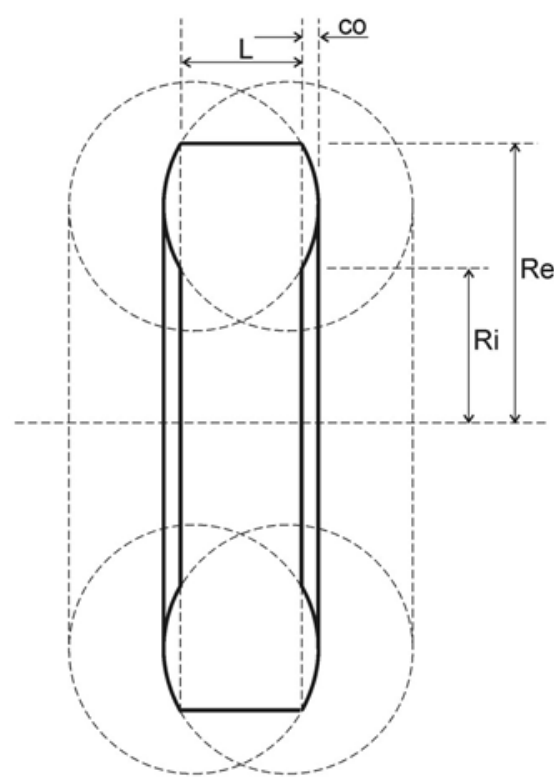

c. Membrane model

Figure 2.2 - Membrane model surfaces

7 - Concerning to the loads at the interaction tire-ground, the region of the tread in contact with the ground is isolated, and the corresponding force systems are applied to this region. It is considered six (6) distributed force systems acting in this region. The whole set of forces, in the absence of inertia forces (no acceleration), constitutes a null system (i.e., a force system where the resultant and the moment to any pole are both equal to zero), which implies the static equilibrium of this region. The Figure 2.3 shows five of these systems, corresponding to the tire forces acting in the contact region. The sixtieth system is the reaction of the ground over the contact region. From membrane hypothesis, this reaction system is equal and directly opposite to the combined other four ones. 


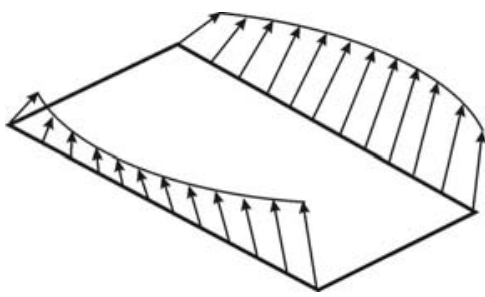

(a) Side walls force systems (two - External (E) and Internal (I))

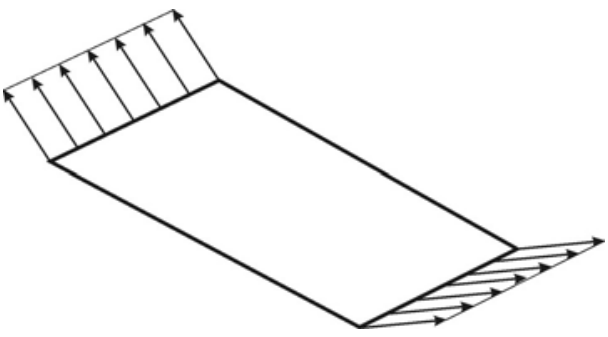

(b) Tread force systems (two - fore and aft)

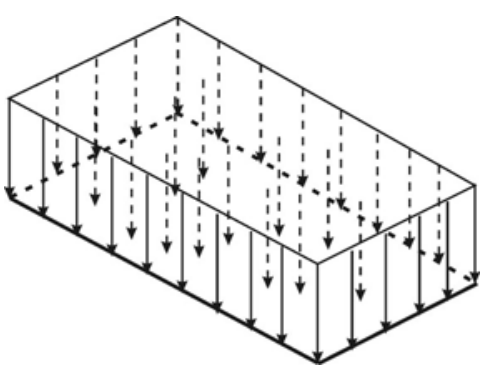

(c) Direct uniform pressure force system

Figure 2.3 Force systems at contact region

A simple physical approach was adopted in this paper, with a straight mathematical formulation, even so it was not rigorously exact from the theoretical viewpoint. This kind of approach is very common and useful from Engineering viewpoint. For example, Timoshenko(1970), in his plain beam theory, adopted the hypothesis that "plane sections remain plane" during the beam bending under transverse loading. This hypothesis is not compatible with the Theory of Elasticity, from where the shear stresses cause a section warping, and they do not remain plane, invalidating the Timoshenko's hypothesis. Even so, this very small "warping effect" is neglected by Timoshenko, and his theory is large and successfully used in Engineering.

\section{MATHEMATICAL MODEL - SIDE WALL SEGMENT}

Let us define the orthogonal positive coordinates system $(O, x, y, z)$, shown in Figure 3.1, fixed to the wheel with exception to the rotation on $\mathrm{Oz}$. It is the equivalent to say that this coordinate system is fixed to the vehicle's wheel shaft.
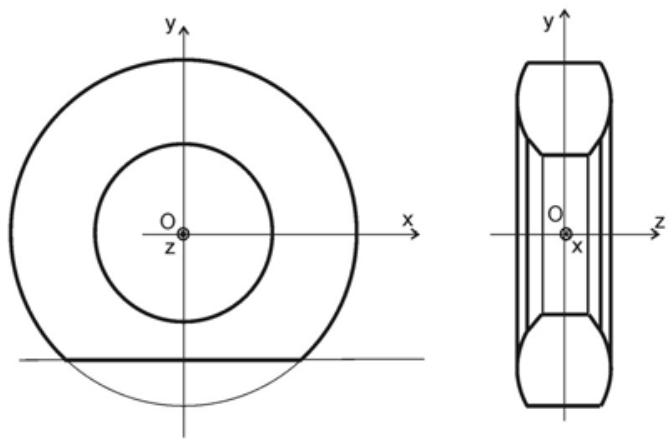

Figure 3.1 - Basic coordinates system

Let us consider the side wall's segment $A B$, as shown in Figure 3.2.

It will be supposed that the stresses state of $A B$ arch is the same of a toroidal surface with internal pressure $p$ and dimensions defined from the parameters $R e, R i$ e $c$. Let us suppose that the stresses remain unchanged for small deformations of the side wall, it means, $D o<<R e$. Then, in the plane of AB arch, the radial stress is given by (Young, 2001):

$\sigma_{r}=p \cdot \rho_{0} / 2 h$ 
where $h$ is the toroid wall thickness, $p$ is the internal pressure and $\rho_{0}$ is the side wall's circumference radius corresponding to $c o$, as shown on Figure 3.2b. The distributed force, per unit length, that the side wall applies on the contact region, acting at $B$, is:

$\vec{f}_{L}=-\sigma_{r} \cdot h \cdot \vec{q}=-p \cdot \rho_{0} / 2 \cdot \vec{q}$

where $\vec{q}$ is the versor indicated in Figure 3.2(b).

It will be supposed that the stresses state of $A B$ arch is the same of a toroidal surface with internal pressure $p$ and dimensions defined from the parameters $R e, R i$ e $c$. Let us suppose that the stresses remain unchanged for small deformations of the side wall, it means, $D o<<R e$. Then, in the plane of AB arch, the radial stress is given by (Young, 2001):

$\sigma_{r}=p \cdot \rho_{0} / 2 h$

where $h$ is the toroid wall thickness. The distributed force, per unit length, that the side wall applies on the contact region, acting at $B$, is:

$\vec{f}_{L}=-\sigma_{r} \cdot h \cdot \vec{q}=-p \cdot \rho_{0} / 2 \cdot \vec{q}$

where $\vec{q}$ is the versor indicated in Figure 3.2(b).

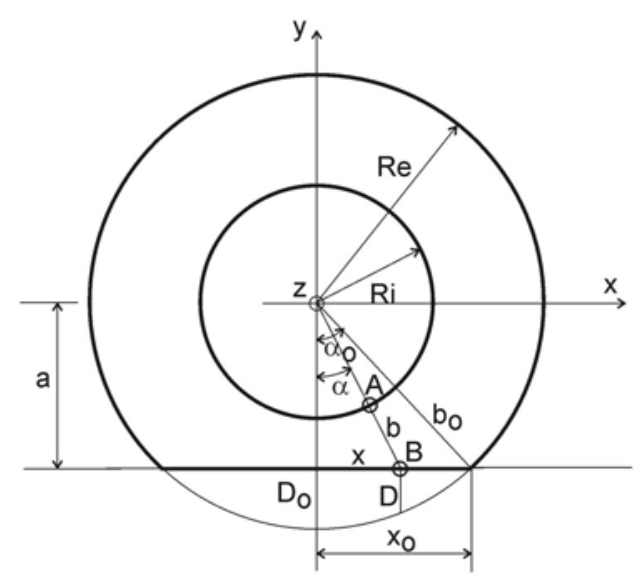

a. Side wall view

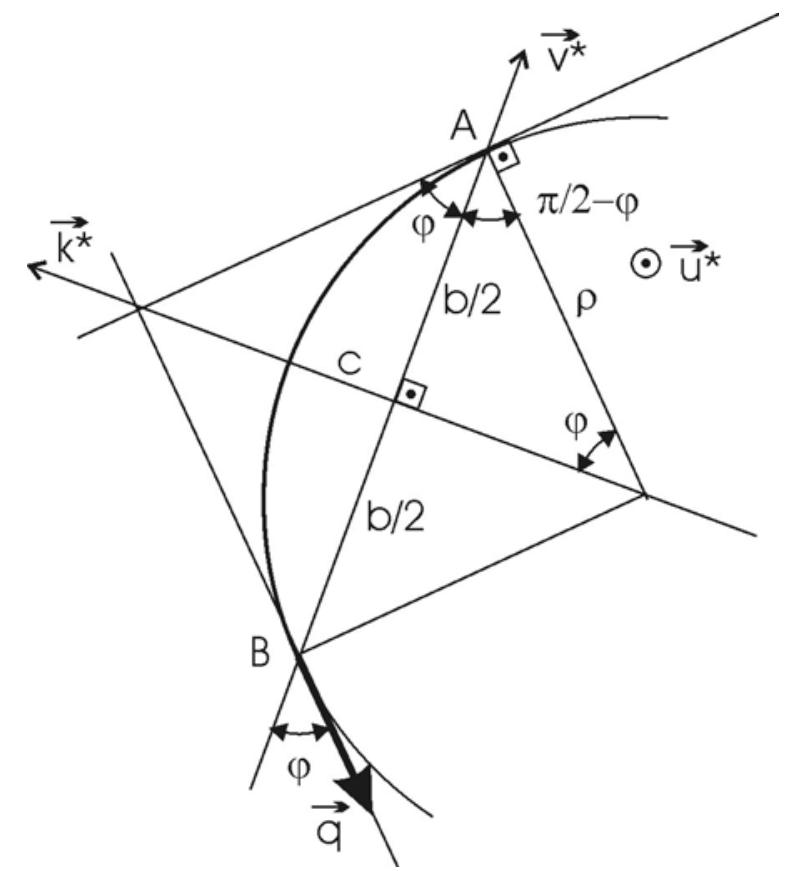

b. Side wall segment

(view of plane orthogonal to $x y$ )

Figure 3.2 Side wall 
The other toroid stress component, orthogonal to the plane of the arch $A B$, self equilibrates when the $A B$ segment is considered and, therefore, is equivalent to zero in this segment.

The length $b o=R e-R i$ and the parameter co correspond to the side wall segment region out of the contact extension; $b$ and $c$ correspond to the deformed side wall region, along to the contact region.

For a generic tire loading, the points $A$ and $B$ will displace, and let us suppose that the arch $A B$ remains being a circumference arch, defined by the resulting values of $b$ and $c$. The direction of the versor $\vec{q}$ will change, due to the changes of the line $A B$ direction and the curvature of the arch $A B$. Then, in equation (2), the force $\vec{f}_{L}$ applied in B will have constant modulus, changing only its direction (same of $\vec{q}$ ) as function of the load case.

From Figure 2.2(b), it is seen that the versor $\vec{q}$ direction is defined by the angle $\varphi$. From membrane hypothesis, the length of the arch $A B$ remains constant and it will be adopted the following simplified condition, valid in principle for small deformations (i.e., $R e-R i>>D 0$ ):

$$
\begin{aligned}
& \left(\frac{b}{2}\right)^{2}+c^{2}=2 \rho c=c t e=\left(\frac{b_{0}}{2}\right)^{2}+c_{0}^{2}=2 \rho_{0} c_{0}=F F^{2} \Rightarrow \\
& \Rightarrow c=\sqrt{F F^{2}-\left(\frac{b}{2}\right)^{2}}
\end{aligned}
$$

Then, it is possible to write the following geometric relationships:

$\rho^{2}=\left(\frac{b}{2}\right)^{2}+(\rho-c)^{2} \Rightarrow \rho=\frac{\left(\frac{b}{2}\right)^{2}+c^{2}}{2 c}=\frac{F F^{2}}{2 \sqrt{F F^{2}-\left(\frac{b}{2}\right)^{2}}}$

$\sin \varphi=\frac{b / 2}{\rho}=\frac{b c}{\left(\frac{b}{2}\right)^{2}+c^{2}}=\frac{b \cdot \sqrt{F F^{2}-\left(\frac{b}{2}\right)^{2}}}{F F^{2}}$

$\cos \varphi=\frac{\rho-c}{\rho}=\frac{\left(\frac{b}{2}\right)^{2}-c^{2}}{\left(\frac{b}{2}\right)^{2}+c^{2}}=\frac{2\left(\frac{b}{2}\right)^{2}-F F^{2}}{F F^{2}}$

Using the versors $\left(\overrightarrow{u^{*}}, \overrightarrow{v^{*}}, \overrightarrow{k^{*}}\right)$, shown in Figure 3.2(b), as a local orthogonal positive coordinates system, the versor $\vec{q}$ may be expressed in components:

$\vec{q}=-\cos \varphi \overrightarrow{v^{*}}-\sin \varphi \overrightarrow{k^{*}}$

And, thus:

$\vec{f}_{L}=\frac{-p \cdot \rho_{0}}{2}\left(-\cos \varphi \overrightarrow{v^{*}}-\sin \varphi \overrightarrow{k^{*}}\right)$

with: $\rho_{0}=F F^{2} /(2 . c o)$ 


\section{VERTICAL LOADING AND FORCES (VERTICAL DEFLECTION)}

\section{$\underline{4.1 \text { - Side wall segment }}$}

This case corresponds to the forces systems shown in the case (a.1) of Figure 2.3.

In the case of vertical deflection only, the relationship between the local side wall versors $\left(\overrightarrow{u^{*}}, \overrightarrow{v^{*}}, \overrightarrow{k^{*}}\right)$ and the wheel versors $(\vec{\imath}, \vec{\jmath}, \vec{k})$ shown in Figure 3.1, for the external side wall surface (E), will be:

$\overrightarrow{u_{E}^{*}}=\cos \alpha \vec{\imath}+\sin \alpha \vec{\jmath}$

$\overrightarrow{v_{E}^{*}}=-\sin \alpha \vec{\imath}+\cos \alpha \vec{\jmath}$

$\overrightarrow{k_{E}^{*}}=\vec{k}$

where, using the Figure 3.2a:

$\sin \alpha=\frac{x}{R i+b}=\frac{\sqrt{(R i+b)^{2}-a^{2}}}{R i+b}$

and

$\cos \alpha=\frac{a}{R i+b}$

Therefore, the distributed force applied in the tire external side wall region will be given by:

$\vec{f}_{L E}=-p \cdot \rho o \cdot[\cos \varphi \cdot \sin \alpha \vec{\imath}-\cos \varphi \cdot \cos \alpha \vec{\jmath}-\sin \varphi \vec{k}]$

and its resultant will be:

$\vec{F}_{L E}=\int_{-x o}^{x o} \vec{f}_{L E} d x=$

$=-p \cdot \rho o \cdot\left[\int_{-x o}^{x o} \cos \varphi \cdot \sin \alpha d x \vec{\imath}-\int_{-x o}^{x o} \cos \varphi \cdot \cos \alpha d x \vec{\jmath}-\int_{-x o}^{x o} \sin \varphi d x \vec{k}\right](10 \mathrm{~b})$

Changing the integration variable from $x$ to $b$, we obtain the following integral for the vertical component of the resultant force:

$$
\begin{aligned}
F_{L E y}= & \frac{p \cdot \rho_{0}}{2} \int_{-x o}^{x o} \cos \varphi \cdot \cos \alpha d x=p \cdot \rho_{0} \cdot \int_{0}^{x o} \cos \varphi \cdot \cos \alpha d x= \\
& =p \cdot \rho_{0} \cdot \int_{a-R i}^{b o}\left[\frac{2\left(\frac{b}{2}\right)^{2}-F F^{2}}{F F^{2}}\right] \cdot\left[\frac{a}{R i+b}\right] \cdot\left[\frac{R i+b}{\sqrt{(R i+b)^{2}-a^{2}}}\right] d b= \\
& =\frac{p \cdot \rho_{0} \cdot a}{F F^{2}} \cdot\left[\frac{1}{2} \int_{a-R i}^{b o} \frac{b^{2}}{\sqrt{(R i+b)^{2}-a^{2}}} d b-F F^{2} \cdot \int_{a-R i}^{b o} \frac{d b}{\sqrt{(R i+b)^{2}-a^{2}}}\right]=
\end{aligned}
$$


$=\frac{p \cdot a^{3}}{8 \cdot c o} \cdot\left\{\left(\frac{R e}{a}-4 \frac{R i}{a}\right) \sqrt{\left(\frac{R e}{a}\right)^{2}-1}+\left[2\left(\frac{R i}{a}\right)^{2}+1-\frac{4 \cdot F F^{2}}{a^{2}}\right] \cdot \ln \left[\sqrt{\left(\frac{R e}{a}\right)^{2}-1}+\left(\frac{R e}{a}\right)\right]\right\}$

In this case of vertical load only, the vertical component of the resultant for the tire internal side wall surface (I) will be, by symmetry:

$F_{L I y}=F_{L E y}$

\section{$\underline{4.2-\text { Tread }}$}

This case corresponds to the forces systems shown in case (b.1) of Figure 2.3.

Let us consider a cylinder with radius $R e$ and internal pressure $p^{*}$.

Let us define this pressure $p^{*}$ as the sum of the internal gas pressure plus the "equivalent pressure" $p$ ', corresponding to the radial loads applied by both side walls on the tread, obtained from equation (1), observing Figure 2.2b (where $\varphi_{0}$ is the value of $\varphi$ at the unloaded condition), and according to equations (8), with $L$ being the tread's width:

$p^{\prime}=-p \cdot \rho_{0} \cdot \frac{\cos \varphi_{0}}{L} \Rightarrow p^{*}=p \cdot\left(L-\rho_{0} \cdot \cos \varphi_{0}\right) / L$

The traction force, applied on the contact region by the cylinder wall at $B$, at the forward side (front) of the contact area, by unit length, will be given by (Young, 2001):

$\vec{f}_{C f}=-p^{*} \cdot \operatorname{Re} \cdot \vec{q}_{C f}$

with $\vec{q}_{C f}=-\cos \alpha_{0} \vec{\imath}-\sin \alpha_{0} \vec{\jmath}$,

where:

$\cos \alpha_{0}=\frac{R e-D o}{R e}=1-\frac{D o}{R e}=\frac{a}{R e}$

and

$\sin \alpha_{0}=\sqrt{1-\cos ^{2} \alpha_{0}}=\frac{\sqrt{R e^{2}-(R e-D o)^{2}}}{R e}=\sqrt{\frac{D o}{R e}\left(2-\frac{D o}{R e}\right)}=\sqrt{1-\left(\frac{a}{R e}\right)^{2}}$ 


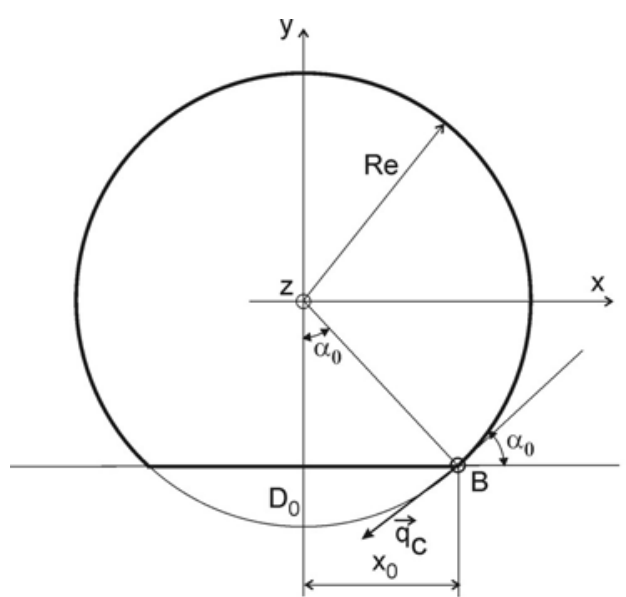

Figure 4.1 - Tread

Thus, the vertical resultant applied in the tread, with width L, corresponding to the frontal region of the contact area, will be:

$$
\begin{aligned}
F_{C f y}= & p^{*} \cdot \text { Re.L. } \sin \alpha_{0}=p^{*} \cdot R e \cdot L \cdot \sqrt{1-\left(\frac{a}{R e}\right)^{2}}=p^{*} \cdot a \cdot L \cdot \sqrt{\left(\frac{R e}{a}\right)^{2}-1}= \\
& =p\left(L-\rho_{0} \cdot \cos \varphi_{0}\right) \cdot a \cdot \sqrt{\left(\frac{R e}{a}\right)^{2}-1}
\end{aligned}
$$

Taking equations (4) e (6), with $b=b o=R e-R i$, one gets:

$\rho_{0}=\frac{4 c o^{2}-(R e-R i)^{2}}{8 c o}$

and

$\cos \varphi_{0}=\frac{\rho_{0}-c o}{\rho_{0}}$

Substituting these two expressions in the previous equation, it results in:

$F_{C f y}=p \cdot a\left[L-\frac{4 \cdot c o^{2}+(R e-R i)^{2}}{8 . c o} \cdot\left(\frac{\rho_{0}-c o}{\rho_{0}}\right)\right] \cdot \sqrt{\left(\frac{R e}{a}\right)^{2}-1}$

By symmetry, the rear force also comes:

$F_{C r y}=F_{C f y}$

\section{$\underline{4.3-\text { Direct pressure }}$}

The vertical resultant of the pressure applied over the contact region, as shown in Figure 2.3, case (c.1), will be:

$F_{p}=-p \cdot\left(2 \cdot x_{0}\right) \cdot L=-2 p \cdot L \cdot D o \sqrt{\frac{2 R e}{D o}-1}=-2 p \cdot L \cdot a \sqrt{\left(\frac{R e}{a}\right)^{2}-1}$

\section{4 - Relationship between vertical load and vertical deflection}


The equilibrium condition on vertical direction gives the expression of the road reaction's resultant $F_{R y}$, as a function of the vertical deflection $D_{0}$ :

$$
\begin{aligned}
& F_{R y}\left(D_{0}\right)=-\left(2 \cdot F_{L E y}+2 \cdot F_{C f y}+F_{p}\right) \quad= \\
& \Rightarrow F_{R y}=-\frac{p \cdot a^{3}}{4 \cdot c o} \cdot\left[\left(\frac{R e}{a}-4 \frac{R i}{a}\right) \sqrt{\left(\frac{R e}{a}\right)^{2}-1}\right]- \\
& -\frac{p \cdot a^{3}}{4 \cdot c o} \cdot\left[2\left(\frac{R i}{a}\right)^{2}+1-\frac{4 \cdot c o^{2}+(R e-R i)^{2}}{a^{2}}\right] \cdot \ln \left[\sqrt{\left(\frac{R e}{a}\right)^{2}-1}+\left(\frac{R e}{a}\right)\right]+ \\
& + \text { 2.p.a. }\left(\frac{(R e-R i)^{2}-4 c o^{2}}{8 c o}\right) \cdot \sqrt{\left(\frac{R e}{a}\right)^{2}-1}
\end{aligned}
$$

where:

$a=R e-D_{0}$

\section{COMPARISON OF RESULTS}

With the purpose of evaluating this mehtodology, values of vertical forces and deflections were calculated for different pressure, using the expression (22), and compared with measured data. Three different tire types commonly used in passenger cars were selected. Namely: tire for small passenger cars (figures 5.2 and 5.5), high performance tire (figure 5.3) and tire used in SUV vehicles (figure 5.4). All these comparisons are shown in the next figures.

The following approximations were used in the tires models:

Internal radius (effective position of the bead bundle):

$R i=\mathrm{DD} / 2+5 \mathrm{~mm}$

External radius (effective position of the tread's mean surface):

$R e=\mathrm{DD} / 2+\mathrm{AA}-15 \mathrm{~mm}$

Curvature or bulging parameter:

$c o=$ estimative, depending on the tire and the wheel

Tread width:

$L=\mathrm{LL}-2 * \mathrm{CO}$

where the data from tires are:

LL = "Section Width"

AA $=$ "Section Height"

DD = "Nominal Rim Diameter" 


\section{1 - Comparison of results - Tire: Pirelli 175/65R14 Cinturato P4}

The Pirelli 175/65R14 Cinturato P4 type tire, commonly used in small passenger cars, is selected due to its large use in Brazil. In this case, the maximum applied load per tire is around $600 \mathrm{kgf}$ and the pressure ranged from $1.93 \mathrm{bar}$ (28 psi) to $2.76 \mathrm{Bar}$ (40 psi). In the load range from 300 to $600 \mathrm{kgf}$, the obtained values differ less than $10 \%$ from the experimental data. In this case:

$\mathrm{Ri}=(14 * 25.4) / 2+5=182.8 \mathrm{~mm}=0.1828 \mathrm{~m}$

$\operatorname{Re}=(14 * 25.4) / 2+(0.65 * 175)-15=276.55 \mathrm{~mm}=0.27655 \mathrm{~m}$

$\mathrm{co}=10 \mathrm{~mm}=0.01 \mathrm{~m}$

$\mathrm{L}=175-2 * 0.01=155 \mathrm{~mm}=0.155 \mathrm{~m}$

\begin{tabular}{|c|c|c|c|c|c|c|c|c|c|c|c|c|c|c|c|}
\hline \multirow{3}{*}{$\begin{array}{l}\text { Meas. } \\
\text { Load } \\
\text { (kgf) }\end{array}$} & \multicolumn{15}{|c|}{ Pressure (psi) } \\
\hline & \multicolumn{3}{|c|}{28} & \multicolumn{3}{|c|}{32} & \multicolumn{3}{|c|}{36} & \multicolumn{3}{|c|}{40} & \multicolumn{3}{|c|}{44} \\
\hline & $\begin{array}{c}\text { Meas. } \\
\text { Defl. } \\
(\mathrm{mm})\end{array}$ & $\begin{array}{l}\text { Calc. } \\
\text { Load } \\
\text { (kgf) }\end{array}$ & $\begin{array}{c}\text { Dif. } \\
\text { Load } \\
(\%)\end{array}$ & $\begin{array}{c}\text { Meas. } \\
\text { Defl. } \\
(\mathrm{mm})\end{array}$ & $\begin{array}{l}\text { Calc. } \\
\text { Load } \\
\text { (kgf) }\end{array}$ & $\begin{array}{l}\text { Dif. } \\
\text { Load } \\
(\%)\end{array}$ & $\begin{array}{l}\text { Meas. } \\
\text { Defl. } \\
(\mathrm{mm})\end{array}$ & $\begin{array}{l}\text { Calc. } \\
\text { Load } \\
\text { (kgf) }\end{array}$ & $\begin{array}{l}\text { Dif. } \\
\text { Load } \\
(\%)\end{array}$ & $\begin{array}{l}\text { Meas. } \\
\text { Defl. } \\
(\mathrm{mm})\end{array}$ & $\begin{array}{l}\text { Calc. } \\
\text { Load } \\
\text { (kgf) }\end{array}$ & $\begin{array}{c}\text { Dif. } \\
\text { Load } \\
(\%)\end{array}$ & $\begin{array}{l}\text { Meas. } \\
\text { Defl. } \\
(\mathrm{mm})\end{array}$ & $\begin{array}{l}\text { Calc. } \\
\text { Load } \\
\text { (kgf) }\end{array}$ & $\begin{array}{c}\text { Dif. } \\
\text { Load } \\
(\%)\end{array}$ \\
\hline 100 & 9 & 77 & $-23.0 \%$ & 8 & 74 & $-25.8 \%$ & 8 & 83 & $-16.6 \%$ & 8 & 93 & $-7.3 \%$ & 8 & 102 & $2.0 \%$ \\
\hline 200 & 16 & 175 & $-12.7 \%$ & 14 & 165 & $-17.3 \%$ & 14 & 186 & $-7.0 \%$ & 13 & 186 & $-6.9 \%$ & 12 & 183 & $-8.6 \%$ \\
\hline 300 & 22 & 271 & $-9.7 \%$ & 20 & 272 & $-9.4 \%$ & 19 & 285 & $-5.0 \%$ & 18 & 294 & $-2.1 \%$ & 17 & 299 & $-0.5 \%$ \\
\hline 400 & 28 & 374 & $-6.6 \%$ & 25 & 368 & $-8.1 \%$ & 24 & 392 & $-2.1 \%$ & 22 & 387 & $-3.3 \%$ & 21 & 399 & $-0.1 \%$ \\
\hline 500 & 34 & 480 & $-4.0 \%$ & 30 & 467 & $-6.5 \%$ & 28 & 481 & $-3.9 \%$ & 26 & 484 & $-3.2 \%$ & 25 & 505 & $1.1 \%$ \\
\hline 555 & 37 & 534 & $-3.8 \%$ & 33 & 528 & $-4.8 \%$ & 31 & 549 & $-1.1 \%$ & 29 & 559 & $0.7 \%$ & 27 & 560 & $0.9 \%$ \\
\hline
\end{tabular}

Table 5.1 - Vertical load and deflection - Tire: Pirelli 175/65R14 Cinturato P4

(Measured data by Pirelli Pneus Brasil)

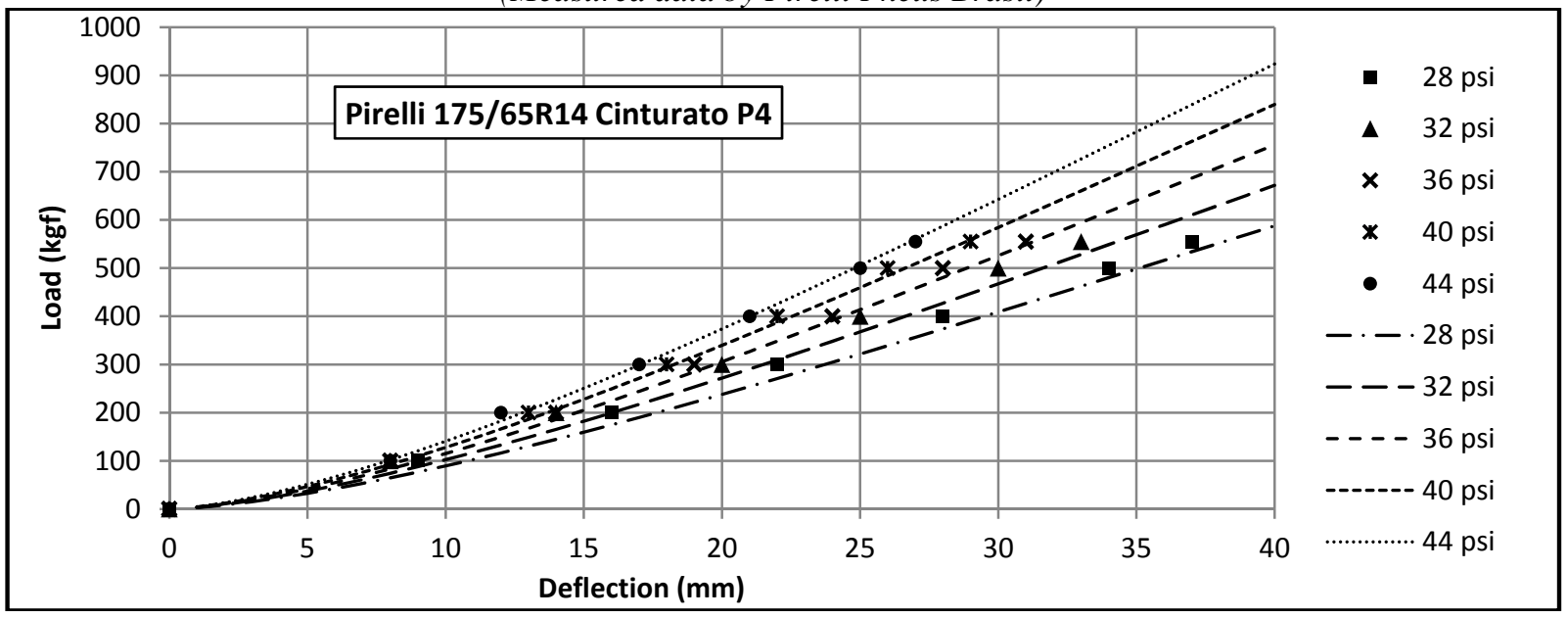

Figure 5.2 - Measured (points) x calculated (lines) vertical deflection - Tire: Pirelli 175/65R14 Cinturato P4 (Measured data by Pirelli Pneus Brasil)

\section{2 - Comparison of results - Tire: Pirelli P7 225/45R17}

The Pirelli P7 225/45R17 type tire was selected as a high performance tire. In this case, the maximum applied load per tire is around $700 \mathrm{kgf}$ and the pressure ranged from $2.00 \mathrm{bar}$ (29 psi) to $2.96 \mathrm{Bar}$ (43 psi). In the load range from 300 to $700 \mathrm{kgf}$, the obtained values differ less than $10 \%$ from the experimental data. In this case: $\mathrm{Ri}=(17 * 25.4) / 2+5=220.9 \mathrm{~mm}=0.2209 \mathrm{~m}$

$\operatorname{Re}=(17 * 25.4) / 2+(0.45 * 225)-15=302.15 \mathrm{~mm}=0.30215 \mathrm{~m}$

$\mathrm{co}=7 \mathrm{~mm}=0.007 \mathrm{~m}$

$\mathrm{L}=225-2 * 7=211 \mathrm{~mm}=0.211 \mathrm{~m}$

\begin{tabular}{|c|c|c|c|c|c|c|c|c|c|c|c|c|c|c|c|c|c|c|}
\hline \multirow[b]{3}{*}{$\begin{array}{c}\text { Meas. } \\
\text { Load } \\
(\mathrm{kgf})\end{array}$} & \multicolumn{18}{|c|}{ Pressure (psi) } \\
\hline & \multicolumn{3}{|c|}{29} & \multicolumn{3}{|c|}{32} & \multicolumn{3}{|c|}{35} & \multicolumn{3}{|c|}{38} & \multicolumn{3}{|c|}{40} & \multicolumn{3}{|c|}{43} \\
\hline & $\begin{array}{l}\text { Meas. } \\
\text { Defl. } \\
(\mathrm{mm})\end{array}$ & $\begin{array}{l}\text { Calc. } \\
\text { Load } \\
\text { (kgf) }\end{array}$ & $\begin{array}{c}\text { Dif. } \\
\text { Load } \\
(\%)\end{array}$ & $\begin{array}{l}\text { Meas. } \\
\text { Defl. } \\
(\mathrm{mm})\end{array}$ & $\begin{array}{l}\text { Calc. } \\
\text { Load } \\
\text { (kgf) }\end{array}$ & $\begin{array}{l}\text { Dif. } \\
\text { Load } \\
(\%)\end{array}$ & $\begin{array}{l}\text { Meas. } \\
\text { Defl. } \\
(\mathrm{mm})\end{array}$ & $\begin{array}{c}\text { Calc. } \\
\text { Load }(\mathrm{kgf})\end{array}$ & $\begin{array}{l}\text { Dif. } \\
\text { Load } \\
(\%)\end{array}$ & $\begin{array}{l}\text { Meas. } \\
\text { Defl. } \\
(\mathrm{mm})\end{array}$ & $\begin{array}{l}\text { Calc. } \\
\text { Load } \\
\text { (kgf) }\end{array}$ & $\begin{array}{l}\text { Dif. } \\
\text { Load } \\
(\%)\end{array}$ & $\begin{array}{l}\text { Meas. } \\
\text { Defl. } \\
(\mathrm{mm})\end{array}$ & $\begin{array}{l}\text { Calc. } \\
\text { Load } \\
\text { (kgf) }\end{array}$ & $\begin{array}{l}\text { Dif. } \\
\text { Load } \\
(\%)\end{array}$ & \begin{tabular}{||c} 
Meas \\
. Defl. \\
$(\mathrm{mm})$
\end{tabular} & $\begin{array}{c}\text { Calc } \\
\text { Load } \\
\text { (kgf) }\end{array}$ & $\begin{array}{c}\text { Dif. } \\
\text { Load } \\
(\%)\end{array}$ \\
\hline 100 & 7 & 71 & $-29,2 \%$ & 7 & 78 & $-21,9 \%$ & 8 & 104 & $3,7 \%$ & 7 & 93 & $-7,2 \%$ & 7 & 98 & $-2,3 \%$ & 7 & 105 & $\begin{array}{c}5,0 \\
\%\end{array}$ \\
\hline 200 & 13 & 172 & $-14,0 \%$ & 12 & 170 & $-15,2 \%$ & 12 & 185 & $-7,3 \%$ & 12 & 201 & $0,7 \%$ & 11 & 187 & $-6,4 \%$ & 11 & 201 & $\begin{array}{c}0,7 \\
\%\end{array}$ \\
\hline 300 & 18 & 271 & $-9,7 \%$ & 17 & 276 & $-7,9 \%$ & 17 & 302 & $0,7 \%$ & 16 & 302 & $0,5 \%$ & 15 & 290 & $-3,3 \%$ & 15 & 312 & $\begin{array}{l}4,0 \\
\%\end{array}$ \\
\hline 400 & 23 & 377 & $-5,7 \%$ & 21 & 369 & $-7,9 \%$ & 21 & 403 & $0,8 \%$ & 20 & 410 & $2,4 \%$ & 19 & 402 & $0,5 \%$ & 19 & 432 & $\begin{array}{c}8,1 \\
\%\end{array}$ \\
\hline
\end{tabular}




\begin{tabular}{|l||c|c|c||c|c|c||c|c|c||c|c|c||c|c|c||c|c|c|}
500 & 28 & 489 & $-2,3 \%$ & 26 & 490 & $-2,1 \%$ & 25 & 509 & $1,7 \%$ & 24 & 523 & $4,7 \%$ & 23 & 521 & $4,1 \%$ & 22 & 527 & $\begin{array}{c}5,5 \\
\%\end{array}$ \\
\hline 600 & 33 & 602 & $0,4 \%$ & 30 & 589 & $-1,8 \%$ & 29 & 617 & $2,9 \%$ & 28 & 640 & $6,7 \%$ & 27 & 643 & $7,2 \%$ & 25 & 625 & $\begin{array}{c}4,2 \\
\%\end{array}$ \\
\hline 670 & 36 & 671 & $0,1 \%$ & 33 & 665 & $-0,8 \%$ & 32 & 699 & $4,4 \%$ & 30 & 700 & $4,4 \%$ & 29 & 705 & $5,3 \%$ & 28 & 725 & $\begin{array}{c}8,2 \\
\%\end{array}$ \\
\hline
\end{tabular}

Table 5.2 - Vertical load and deflection - Tire: Pirelli P7 225/45R17

(Measured data by Pirelli Pneus Brasil)

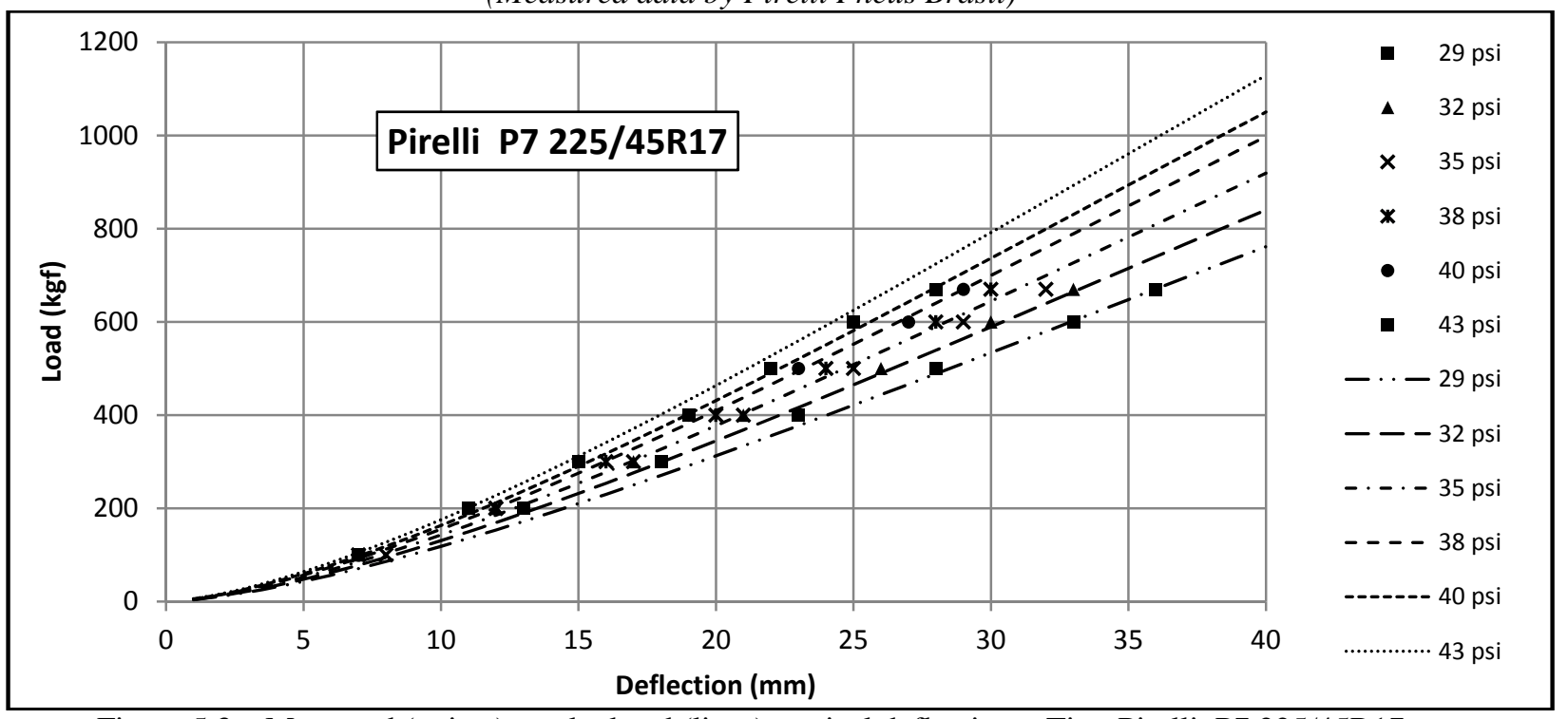

Figure 5.3 - Measured (points) x calculated (lines) vertical deflection - Tire: Pirelli P7 225/45R17

(Measured data by Pirelli Pneus Brasil)

\section{3 - Comparison of results - Tire: Pirelli Scorpion ATR P245/70 R16}

The Pirelli Scorpion ATR P245/70 R16 type tire, used in SUV's, is evaluated. In this case, the maximum applied load per tire is around $1000 \mathrm{kgf}$ and the pressure ranged from $2.00 \mathrm{bar}$ ( $29 \mathrm{psi}$ ) to $3.86 \mathrm{Bar}$ (56 psi). In the load range from 400 to $800 \mathrm{kgf}$, the obtained values differ less than 10\% from the experimental data (except in the case of $400 \mathrm{kgf}$ and $56 \mathrm{psi}$, where the difference was about 13\%). In this case:

$\mathrm{Ri}=(16 * 25.4) / 2+5=208.2 \mathrm{~mm}=0.2082 \mathrm{~m}$

$\operatorname{Re}=(16 * 25.4) / 2+(0.70 * 245)-15=359.7 \mathrm{~mm}=0.3597 \mathrm{~m}$

$\mathrm{co}=13 \mathrm{~mm}=0.013 \mathrm{~m}$

$\mathrm{L}=245-2 * 13=219 \mathrm{~mm}=0.219 \mathrm{~m}$

\begin{tabular}{|c|c|c|c|c|c|c|c|c|c|c|c|c|c|c|c|}
\hline \multirow{3}{*}{$\begin{array}{c}\text { Meas. } \\
\text { Load } \\
(\mathrm{kgf})\end{array}$} & \multicolumn{15}{|c|}{ Pressure (psi) } \\
\hline & \multicolumn{3}{|c|}{29} & \multicolumn{3}{|c|}{36.3} & \multicolumn{3}{|c|}{42.1} & \multicolumn{3}{|c|}{49.3} & \multicolumn{3}{|c|}{56.6} \\
\hline & $\begin{array}{c}\text { Meas. } \\
\text { Defl. } \\
(\mathrm{mm})\end{array}$ & $\begin{array}{l}\text { Calc. } \\
\text { Load } \\
\text { (kgf) }\end{array}$ & $\begin{array}{l}\text { Dif. } \\
\text { Load } \\
(\%)\end{array}$ & $\begin{array}{l}\text { Meas. } \\
\text { Defl. } \\
(\mathrm{mm})\end{array}$ & $\begin{array}{l}\text { Calc. } \\
\text { Load } \\
\text { (kgf) }\end{array}$ & $\begin{array}{l}\text { Dif. } \\
\text { Load } \\
(\%)\end{array}$ & $\begin{array}{l}\text { Meas. } \\
\text { Defl. } \\
(\mathrm{mm})\end{array}$ & $\begin{array}{l}\text { Calc. } \\
\text { Load } \\
\text { (kgf) }\end{array}$ & $\begin{array}{l}\text { Dif. } \\
\text { Load } \\
(\%)\end{array}$ & $\begin{array}{l}\text { Meas. } \\
\text { Defl. } \\
(\mathrm{mm})\end{array}$ & $\begin{array}{l}\text { Calc. } \\
\text { Load } \\
\text { (kgf) }\end{array}$ & $\begin{array}{l}\text { Dif. } \\
\text { Load } \\
(\%)\end{array}$ & $\begin{array}{l}\text { Meas. } \\
\text { Defl. } \\
(\mathrm{mm})\end{array}$ & $\begin{array}{l}\text { Calc. } \\
\text { Load } \\
\text { (kgf) }\end{array}$ & $\begin{array}{l}\text { Dif. } \\
\text { Load } \\
(\%)\end{array}$ \\
\hline 200 & 10 & 136 & $-32,1 \%$ & 9 & 146 & $-27,2 \%$ & 8 & 142 & $-28,9 \%$ & 7 & 137 & $-31,6 \%$ & 6 & 125 & $-37,5 \%$ \\
\hline 400 & 20 & 369 & $-7,9 \%$ & 17 & 366 & $-8,5 \%$ & 16 & 389 & $-2,7 \%$ & 14 & 376 & $-6,0 \%$ & 12 & 345 & $-13,7 \%$ \\
\hline 600 & 28 & 590 & $-1,6 \%$ & 25 & 631 & $5,2 \%$ & 22 & 612 & $2,0 \%$ & 20 & 626 & $4,4 \%$ & 18 & 619 & $3,2 \%$ \\
\hline 800 & 36 & 832 & $4,0 \%$ & 31 & 850 & $6,3 \%$ & 28 & 857 & $7,1 \%$ & 25 & 858 & $7,2 \%$ & 23 & 876 & $9,5 \%$ \\
\hline 969 & 43 & 1053 & $8,7 \%$ & 37 & 1080 & $11,5 \%$ & 33 & 1074 & $10,8 \%$ & 30 & 1104 & $13,9 \%$ & 27 & 1096 & $13,1 \%$ \\
\hline
\end{tabular}

Table 5.3 - Vertical load and deflection - Tire: Pneu Pirelli Scorpion ATR P245/70 R16

(Measured data by Pirelli Pneus Brasil) 


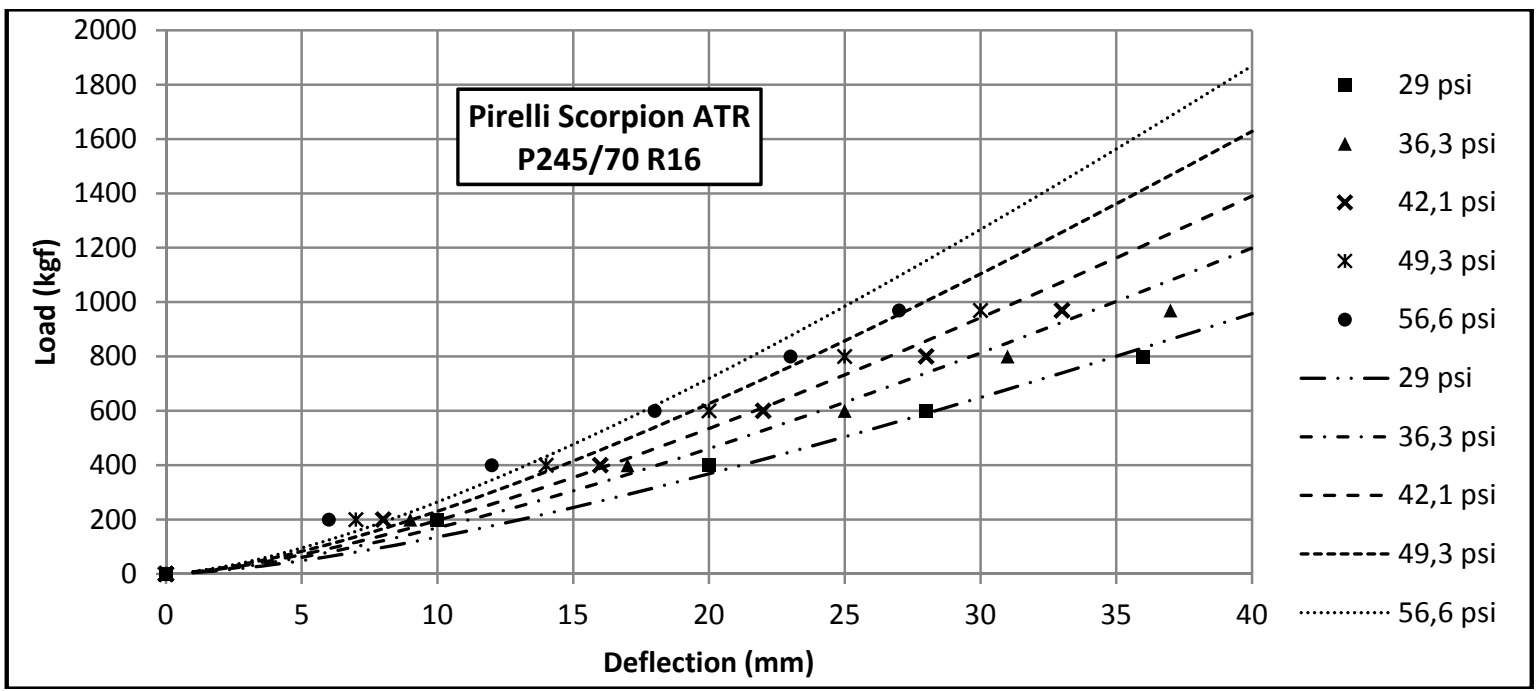

Figure 5.4 - Measured (points) x calculated (lines) vertical deflection - Tire: Pirelli Scorpion ATR P245/70 R16 (Measured data by Pirelli Pneus Brasil)

\section{4 - Comparison of results - Tire: Pneu Good-Year GPS3 Sport 185/65R14 86T}

The small passenger cars tire (Good-Year GPS3 Sport 185/65R14 86T) is evaluated. In this case the load per tire reach $1000 \mathrm{kgf}$ and the pressure ranged from $2.00 \mathrm{bar}$ (29 psi) to $2.96 \mathrm{Bar}$ (43 psi). In the load range from 400 to $1000 \mathrm{kgf}$, the obtained values differ about or less than $11 \%$ from the experimental data. In this case:

$\mathrm{Ri}=(14 * 25.4) / 2+5=182.8 \mathrm{~mm}=0.1828 \mathrm{~m}$

$\operatorname{Re}=(14 * 25.4) / 2+(0.65 * 185)-15=283.05 \mathrm{~mm}=0.28305 \mathrm{~m}$

co $=9 \mathrm{~mm}=0.09 \mathrm{~m}$

$\mathrm{L}=185-2 * 9=167 \mathrm{~mm}=0.167 \mathrm{~m}$

\begin{tabular}{|c|c|c|c|c|c|c|}
\hline \multirow{3}{*}{$\begin{array}{c}\text { Meas. } \\
\text { Load } \\
(\mathrm{kgf})\end{array}$} & \multicolumn{6}{|c|}{ Pressure (psi) } \\
\hline & \multicolumn{3}{|c|}{29} & \multicolumn{3}{|c|}{43.5} \\
\hline & $\begin{array}{l}\text { Meas. Defl. } \\
(\mathrm{mm})\end{array}$ & $\begin{array}{l}\text { Calc. Load } \\
\text { (kgf }\end{array}$ & $\begin{array}{l}\text { Dif. } \\
\text { Load } \\
(\%)\end{array}$ & $\begin{array}{l}\text { Meas. Defl. } \\
(\mathrm{mm})\end{array}$ & $\begin{array}{l}\text { Calc. Load } \\
\text { (kgf }\end{array}$ & $\begin{array}{l}\text { Dif. } \\
\text { Load } \\
(\%)\end{array}$ \\
\hline 182,9 & 10,2 & 115 & $-36,9 \%$ & 7,6 & 113 & $-38,2 \%$ \\
\hline 315,6 & 17,8 & 254 & $-19,4 \%$ & 13,2 & 250 & $-20,7 \%$ \\
\hline 416,8 & 23,8 & 379 & $-9,1 \%$ & 17,4 & 370 & $-11,3 \%$ \\
\hline 600,7 & 32,6 & 575 & $-4,3 \%$ & 24,7 & 598 & $-0,5 \%$ \\
\hline 786,0 & 42,7 & 807 & $2,6 \%$ & 31,7 & 832 & $5,8 \%$ \\
\hline 972,8 & 51,5 & 1007 & $3,5 \%$ & 38,8 & 1076 & $10,6 \%$ \\
\hline
\end{tabular}

Table 5.4 - Vertical load and deflection - Tire: Pneu Good-Year GPS3 Sport 185/65R14 86 T (Measured data by Volkswagen do Brasil)

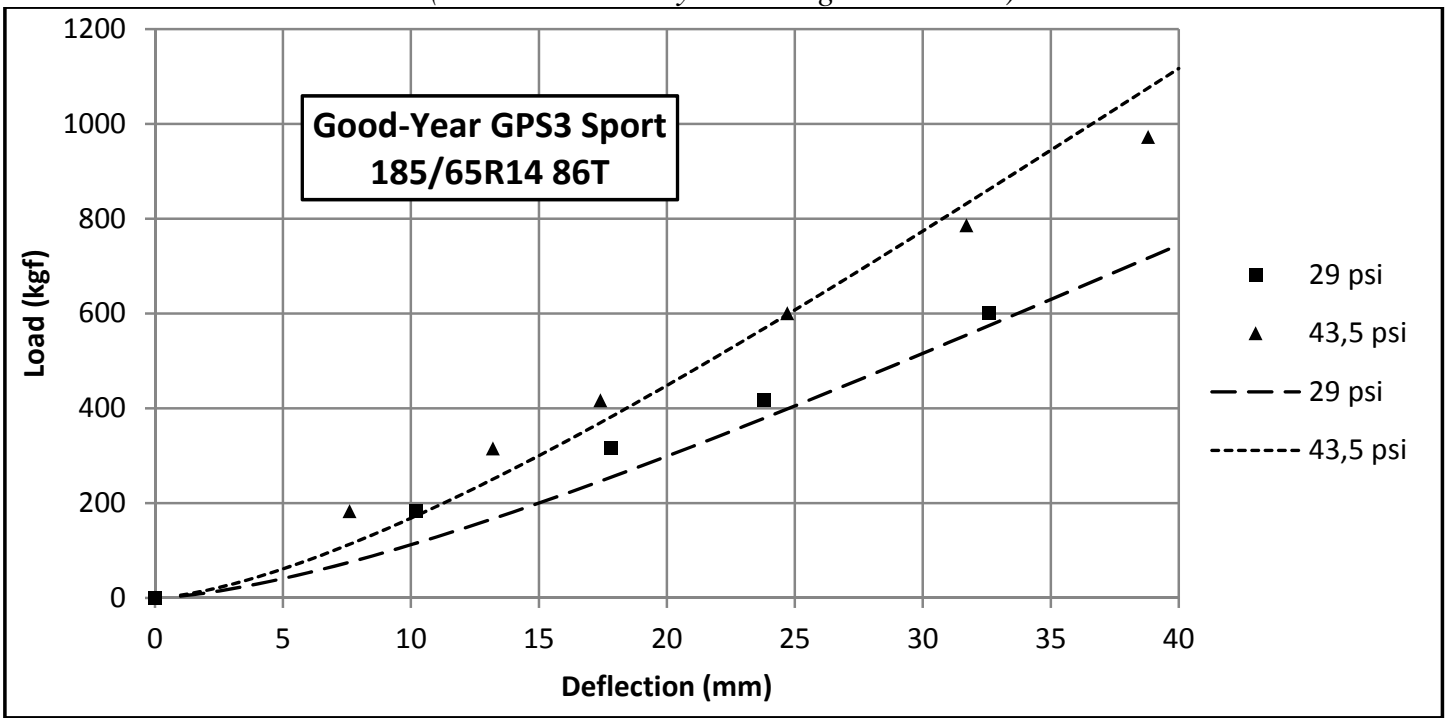

Figure 5.5 - Measured (points) x calculated (lines) vertical deflection - Tire: Good-Year GPS3 Sport 185/65R14 $86 \mathrm{~T}$ 


\section{CONCLUSIONS AND COMMENTS}

A new model for the tire is proposed based in the membrane concept, or thin walled involucres hypothesis, which physical and mathematically represents the tire vertical structural behavior. The model proposed is simple, purely geometric and therefore clearly understood from the physical point of view. Results obtained with the model shows good agreement with experimental data from different tires and inflation pressure.

1 - An essentially theoretical approach was adopted in this model, in the sense that it does not require any empirical data.

2 - The membrane or thin walled involucre model, here adopted, does not depend of the tire material, but only on its geometry. The tire model is defined by only four independent geometric parameters: $R e, R i, c o$ and $L$, obtained directly from its dimensions.

3 - The calculated data from the proposed model were compared with measured data from four quite different tire types - for small cars, for high performance race car and for heavy duty SUV's. In all the cases, the differences between measured and calculated data were lower than $5 \%$ in the normal range of pressure and loading. In extreme ranges (too high or too low), these differences were about $30 \%$. It is relevant to note that, for instance, on Table 5.1, for $100 \mathrm{kgf}$, the measured tire deflection is $9 \mathrm{~mm}$ for $28 \mathrm{psi}$, and $8 \mathrm{~mm}$ (constant) from 32 to 44 psi. It means that the measured data suggests that the deflection does not depend on the tire pressure in this range. For more significant comparisons, the measured data would need to be more accurate.

4 - The proposed model presents simplicity of use and capacity to represent quite well the tire mechanical behavior. It may be significantly useful in situations of developing or optimizing vehicles suspension systems.

5 - Other situations with lateral loads, curves, slips and dynamical structural behavior and load conditions, will be approached in future article.

\section{ACKNOWLEDGEMENTS}

The authors would like to register here their gratefulness to Mr. Argemiro Costa, from Pirelli do Brasil, and Mr. Leandro Macedo, from Volkswagen do Brasil, by the support to this work.

\section{BIBLIOGRAPHY}

, (2011)- Car Bibles: The Wheel and Tyre Bible, URL: http://www.carbibles.com/tyre_bible.html, accessed January.

BÖHM, F. (1966) - Mechanik des Gürtelreifens, Ingenieur Archiv 35, 82-101, Germany.

KUNG, L.E., SOEDEL W., YANG, T.Y. (1986) Free-vibration of a pneumatic tire-wheel unit using a ring on an elastic-foundation and a finite-element model. Journal of Sound and Vibration Volume: 107 Issue: 2 Pages: 181-194 Published: JUN 81986

LECOMTE, C., GRAHAM W.R., DALE M. (2010) A shell model for tyre belt vibrations. Journal of Sound and Vibration Volume: 329 Issue: 10 Pages: 1717-1742 Published: MAY 102010 
MERIAN, J. L. et KRAIGE, L. G. (2008) - Engineering Mechanics: Statics, 6th Edition, Wiley, ISBN-10: 0471787027, ISBN-13: 978-0471787020, USA.

NAKASHIMA H., WONG, J.Y. (1993) A 3-dimensional tire model by the finite-element method. journal of terramechanics, Volume: 30, Issue: 1, Pages: 21-34.

PACEJKA, H. B. (2006) - Tire and vehicle dynamics, 2nd Edition, SAE International, USA.

PACEJKA, H. B., (2002) Tyre and Vehicle Dynamics, SAE Publication R372.

PACEJKA, H. B., SHARP R. S. (1991) Shear force development by pneumatic tires in steady-state conditions - a review of modeling aspects. Vehicle System Dynamics. Volume: 20, issue: 3-4, Pages: 121-175.

PISSARENKO, G. S.; IAKOVLEV, A. P. et MATVEIEV, V. V. (1985) - Prontuário de resistência de materiais, Ed. Mir, Moscow, URSS.

TIMOSHENKO, S. P. et GOODIER, J. N. (1970) - Theory of Elasticity, 3rd edition, McGraw Hill, ISBN-10: 0070858055; ISBN-13: 978-0070858053, USA.

TIMOSHENKO, S. P. et WOINOWSKY-KRIEGER, S. (1964) - Theory of Plates and Shells, 2nd edition, McGraw Hill, ISBN-10: 0070858209; ISBN-13: 978-0070858206, USA.

VIL'KE, V. G. et DVORNIKOV, M. V. (1998) - The rolling of a wheel with a pneumatic tire on a plane, J. Appl. Maths Mechs, vol. 62, No. 3, pp. 359-369, Pergamon, USA.

VIL'KE, V. G. et KOZHEVNIKOV, I. F. (2001) - The rolling of a wheel with a reinforced tire along a plane without slip, J. Appl. Maths Mechs, vol. 65, No. 6, pp. 915-927, Pergamon, USA.

VIL'KE, V. G. et KOZHEVNIKOV, I. F. (2004) - The rolling of a wheel with a reinforced tire along a plane with slipping, J. Appl. Maths Mechs, vol. 68, pp. 909-921, Elsevier, USA.

YONG, R.N., FATTAH, E.A., and BOONSINSUK, P. (1978) Analysis and prediction of tire-soil interaction and performance using finite elements, J. Terramechanics 15 (1) (1978), pp. 4363.

YOUNG, W. et BUDYNAS, R. (2001) - Roark's Formulas for Stress and Strain, 7th Edition, McGraw-Hill, ISBN-10: 007072542X, ISBN-13: 978-0070725423, USA.

ZACHOW, D. (1997) 3D membrane shell model in application of a tractor and PKW tyre. VEHICLE SYSTEM DYNAMICS Volume: 27 Pages: 163-172 Supplement: Suppl. S Published: 1997 